\title{
Molecular and cellular mechanisms of joint destruction in rheumatoid arthritis: two cellular mechanisms explain joint destruction?
}

\author{
Steffen Gay, Renate E Gay, William J Koopman
}

Rheumatoid arthritis (RA) is a chronic systemic disorder of unknown aetiology. Most of its serious and debilitating sequelae derive from progressive destruction of joints. Although early and late stages of this disease may involve distinct processes, the affected joints of symptomatic patients characteristically exhibit overlapping manifestations of three pathobiological phenomena (fig 1):

(1) Inflammation appears to be the basis of joint pain and several systemic manifestations. A large number of inflammatory mediators, including arachidonic acid metabolites, vasoactive amines, and neuropeptides, have been identified in the affected joints of patients with RA, and cytokines such as tumour necrosis factor $\alpha$ and interleukins 1 and 6 (IL-1 and -6) have been implicated in the perpetuation of rheumatoid synovitis. ${ }^{12}$

(2) Abnormal cellular and humoral immune responses represent another hallmark of RA. Autoantibodies, particularly rheumatoid factors (RFs) and antibodies directed against collagen type II, are often present. ${ }^{3}$ Moreover, accumulation of $\mathrm{T}$ lymphocytes, particularly those expressing the CD4+, CDw29 (UCHL $1+/ 4 \mathrm{~B} 4+)$ memory phenotype of the helperinducer subset, occurs in the synovium. Some of these $T$ cells express activation markers on their surfaces. Evidence pointing to a critical role for activated $\mathrm{T}$ cells in the pathogenesis of $\mathrm{RA}$ has fostered the development of several new therapeutic strategies. ${ }^{4}$

(3) Synovial hyperplasia is characterised by proliferating, synovial cells with a transformed appearance ${ }^{5}$ and large numbers of infiltrating macrophages. ${ }^{6}$

The conundrum of RA has puzzled researchers for decades. What is the initial step in the pathogenesis of the disease? The association of certain major histocompatibility complex (MHC) class II molecules with RA has been repeatedly demonstrated (see below). As MHC class II molecules are known to function in the restricted presentation of antigenic peptides to $\mathrm{CD} 4+\mathrm{T}$ cells, ${ }^{7}$ in the shaping of the $\mathrm{CD} 4+\mathrm{T}$ cell receptor repertoire, ${ }^{8}$ as well as the presentation of superantigens to $\mathrm{CD} 4+$ cells, $^{9}$ the $\mathrm{T}$ cell is presumed to have a central role in the pathogenesis of RA. Harris, for example, has suggested that $T$ cells are associated with 'stage 1 ' of the disease. ${ }^{10}$ On the other hand, Firestein and Zvaifler have challenged the importance of $T$ cells in RA based on observations that only

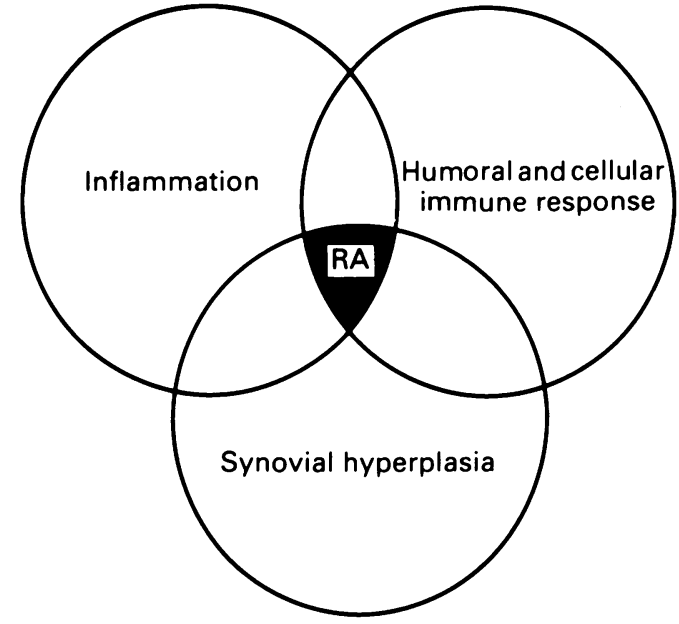

Figure 1 Overlapping manifestations of three pathobiological phenomena present in the affected joints of patients with symptomatic rheumatoid arthritis.

negligible levels of $\mathrm{T}$ cell specific lymphokines (for example, IL-2, IL-3, IL-4, interferon $\gamma$, and tumour necrosis factor $\beta$ ) can be detected in rheumatoid joints. ${ }^{11}$ The latter data can be accommodated by an alternative hypothesisnamely, that induction of RA is favoured by a 'hole' present in the $T$ cell repertoire of susceptible subjects, which results in impaired handling of an aetiologic agent(s), such as a virus. It is of interest in this regard that patients with AIDS expressing HLA-B35 respond to HIV-I with a more accelerated clinical course than patients with AIDS lacking this phenotype. $^{12}$

With regard to the role of inflammation in the pathogenesis of RA (fig 1), our laboratory has been investigating approaches suitable for detecting early evidence of joint destruction, such as the presence of collagen type II fragments in synovial fluid and serum. Although these studies were aimed at the development of an indicator system for monitoring disease activity, they also provided insights into the cellular basis of joint destruction in RA. Surprisingly, we found that the presence of collagen type II fragments in synovial phagocytes did not correlate with the number of white blood cells in the synovial fluid, ${ }^{13}$ suggesting that cartilage destruction in RA may proceed through pathways independent of classic inflammation. Indeed, increasing evidence indicates that synovial cells with a transformed appearance participate in the cartilage/bone destruction characteristic of 
RA. In this review we discuss recent findings supporting roles for both $T$ cell dependent immune responses and hyperplastic synovial cells in the pathogenesis of RA.

\section{$\mathbf{T}$ cell responses in rheumatoid arthritis}

Evidence implicating $T$ cells in the pathogenesis of RA includes the aforementioned strong association between RA and DR alleles sharing a common amino acid sequence motif in the third hypervariability region of their DR $\beta 1$ chains ${ }^{14}$; the prominence of $\mathrm{T}$ cells in synovial mononuclear cell infiltrates, ${ }^{15} 10-15 \%$ of which characteristically express activation markers such as the interleukin 2 receptor (IL-2R) ${ }^{16}$; apparent efficacy of $\mathrm{T}$ cell directed treatments in RA, including cyclosporin ${ }^{17}$ and experimental monoclonal antibodies to $\mathrm{CD} 4^{18-20}$; and resolution of pre-existing $\mathrm{RA}$ in patients developing AIDS. ${ }^{21} 22$

What are $T$ cells responding to in RA? Although a definitive answer remains elusive, some insights have emerged from molecular studies of $\mathrm{T}$ cell receptor diversity in affected joint tissue. Using a quantitative polymerase chain reaction technique, Paliard and colleagues noted expansion of $\mathrm{V} \beta 14+\mathrm{T}$ cells in the synovial fluid of each of nine patients with active RA, despite low expression of V $\beta 14$ among peripheral blood $T$ cells in these patients. $^{23}$ Sequence analyses disclosed oligoclonality of $\mathrm{V} \beta 14$ transcripts in RA synovial fluid. In contrast, enhanced expression of $\mathrm{V} \beta 14$ was not found among synovial fluid $\mathrm{T}$ cells in three arthritic controls (two with Reiter's disease, one with psoriatic arthritis). The results were interpreted as being consistent with an initial activation of V $\beta 14+$ $\mathrm{T}$ cells by a superantigen followed by local expansion of certain $V \beta 14+T$ cell clones by antigens present in the joints of these rheumatoid patients. More recently, Uematsu and coworkers analysed the synovial fluid $T$ cell receptor repertoire of a patient with RA using an inverted polymerase chain reaction approach. ${ }^{24}$ This powerful technique obviates the need for $\mathrm{V}$ region specific or $\mathrm{V}$ region consensus primers, a source of potential bias. Although considerable heterogeneity of synovial fluid $\mathrm{T}$ cell receptor $\mathrm{V} \alpha$ and $\mathrm{V} \beta$ gene usage was noted, a modest two- to threefold enrichment (relative to peripheral blood) of $\mathrm{V} \beta 2 \cdot 1$ and $\mathrm{V} \beta 3 \cdot 1$ transcripts was detected in this patient.

Reasoning that analysis of activated $\mathrm{T}$ cells might be more informative, Howell et al isolated IL-2R+ synovial T cells from five patients with RA and found V $\mathrm{V} 3, \mathrm{~V} \beta 14$, and $V \beta 17$ were expressed in most of the synovial samples. ${ }^{25}$ Dominant rearrangements were seen within these $\mathrm{V} \beta$ families (unlike peripheral blood), consistent with oligoclonal expansion of activated $\mathrm{T}$ cells. Evidence indicating oligoclonal expansion of IL-2 responsive synovial $\mathrm{T}$ cells in RA has also been obtained using restriction fragment analysis, but patterns of $V \alpha$ and $V \beta$ gene expression were not examined in that report. ${ }^{26}$
Preferential expression of particular V $\beta$ families among synovial $T$ cells in $R A$ is consistent with exposure to a superantigen(s). Apparently conflicting results regarding patterns of $T$ cell receptor $V \beta$ expression in $R A$ might reflect the dominant influence of different superantigens. Indeed, distinct patterns of selective $V \beta$ family activation have been shown for different streptococcal ${ }^{27}$ and staphylococcal $^{28}$ toxin superantigens. The parallel increase in $\mathrm{V} \beta 3, \mathrm{~V} \beta 14$, and $\mathrm{V} \beta 17$ seen among activated synovial $\mathrm{T}$ cells in some patients with RA is of particular interest as these V $\beta$ families exhibit considerable sequence homology, especially in the fourth complementarity determining region, implicated as the $V \beta$ binding site for several superantigens. ${ }^{29-31}$ That this pattern of $V \beta$ family expansion might reflect the influence of a superantigen is supported by the finding that Mycoplasma arthritidis mitogen activates human $T$ cells bearing V $\beta 3$ and V $\beta 17 .^{32}$

While a role for superantigens in local $\mathrm{T}$ cell activation in RA is an attractive hypothesis, it is difficult to reconcile the available $\mathrm{T}$ cell receptor repertoire data with that explanation alone. Oligoclonal expansion seen in the aforementioned studies is more consistent with local antigen induced responses. Recent evidence from a study of autoimmune thyroid disease supports this view. Restricted $\mathrm{T}$ cell receptor $\mathrm{V}$ gene expression has been convincingly shown among intrathyroidal $\mathrm{T}$ cells of patients with autoimmune thyroid disease, ${ }^{33}$ and, clearly, a substantial fraction of these $\mathrm{T}$ cells is reactive with thyroidal antigens. ${ }^{34}$

Little information, however, exists about the specificity of synovial T cells in RA. This issue is complicated by evidence that only a fraction of synovial $T$ cells in RA seems to be activated (for example, those cells bearing IL-2R). Nonetheless, it is intriguing that Londei and colleagues found that about $12 \%$ of $\mathrm{T}$ cell clones, isolated from two synovial samples obtained at an interval of 21 months from the same joint of a patient with RA, were reactive with collagen type II. ${ }^{35}$ The epitope specificity of $\mathrm{T}$ cells reactive with collagen type II in RA is unknown. A DR7 restricted CD4+ $T$ cell clone directed against type II collagen, isolated from a healthy subject, recognised an epitope spanning amino acids $271-285$ of the $\alpha 1$ (II) chain located in cyanogen bromide fragment 11 of the molecule. ${ }^{36}$ Interestingly, $\alpha 1$ (II)-cyanogen bromide fragment 11 is thus far the only collagen II fragment clearly shown to be arthritogenic in animal studies. Heat shock proteins are also an attractive target antigen for $T$ cells in RA. These evolutionarily conserved proteins are often the dominant target antigens for immune responses directed against a broad array of microorganisms. In the case of adjuvant arthritis, $T$ cells reactive with an epitope contained in the 65 kilodalton heat shock protein of Mycobacterium tuberculosis can transfer the disease and presumably cross react with an as yet unidentified autoantigen in joint tissue of recipients. ${ }^{37} 38$ Local expression of human 65 kilodalton heat shock protein has been shown in inflamed rheumatoid 
synovium. ${ }^{39}$ Cytotoxic $\mathrm{T}$ cell clones cross reactive with Mycobacteria bovis and human 65 kilodalton heat shock protein have been isolated from the joints of patients with $\mathrm{RA}^{40}$; however, the frequency of $T$ cells reactive with the mycobacterial 65 kilodalton heat shock protein seems to be similar in both peripheral blood and synovial fluid of patients with RA. ${ }^{41}$ Thus a role for $T$ cells reactive with heat shock proteins in the pathogenesis of RA remains unproved.

\section{T cell migration into rheumatoid synovium}

Expression of cell adhesion molecules on endothelial cells and complementary ligands on the surface of circulating leucocytes seems to have a critical role in determining the site of leucocyte emigration and the nature of the leucocytes migrating into an inflammatory lesion. Butcher has proposed that leucocyteendothelial cell recognition requires at least three steps: primary adhesion (transient), leucocyte activation, and activation dependent binding with subsequent leucocyte transmigration. ${ }^{42}$ This model implies that the specificity of endothelial cell/leucocyte interactions is determined by unique combinations of adhesion molecule/ligand interactions operating at each step. Although the adhesion molecule/ligand pairs taking part in the leucocyte/endothelial cell primary adhesion event, also referred to as 'rolling', have not been fully elucidated, it seems that selectin/ carbohydrate ligands mediate this event in the case of neutrophils. ${ }^{43}$ Interestingly, synovial endothelial cells isolated from patients with RA constitutively express endothelial leucocyte adhesion molecule type 1 (ELAM-1) and upregulate expression of this selectin after exposure to IL-1. ${ }^{45}$

Kavanaugh and colleagues obtained evidence that the interaction of leucocyte function associated antigen 1 (LFA-1) with its ligand, intercellular adhesion molecule 1 (ICAM-1), probably has a key role in transendothelial migration of $\mathrm{T}$ cells. ${ }^{46}$ ICAM-1 is also expressed on isolated rheumatoid synovial endothelial cells and is subject to regulation by IL-1. ${ }^{45}$ Binding of $T$ cells to endothelial cells in the absence of expressed LFA-1 occurred through the interaction of very late antigen 4 (VLA-4) and its ligand, vascular cell adhesion molecule 1 (VCAM-1). ${ }^{46}$ More recently, Oppenheimer-Marks et al extended these observations by demonstrating that VCAM-1/VLA-4 interactions predominately mediate binding of $T$ cells to endothelial cells exposed to IL-1, whereas LFA-1/ICAM-1 interactions are crucial to subsequent transendothelial migration of the T cell. ${ }^{47}$

The predominance of memory $T$ cells in rheumatoid synovium had been thought to reflect in situ activation of T cells. Enhanced surface expression of integrins (including VLA-4) on memory (CD45R0+) $\mathrm{T}$ cells as compared with virgin (CD45R0-) $\mathrm{T}$ cells, however, would be expected to lead to selective migration of memory cells into the inflamed synovium of patients with RA. ${ }^{48} 49$ Indeed, CD45R0 + $\mathrm{T}$ cells adhere better to endothelial cells than do CD45R0 - cells. ${ }^{50}$ Retention of these cells in the synovium is probably enhanced by subsequent interactions between adhesion molecules and matrix molecule ligands such as VLA-4 and fibronectin. Local release of cytokines such as IL-1 and IL- 8 with consequent upregulation of endothelial cell adhesion molecules probably promotes differential binding and transmigration of memory $T$ cells into rheumatoid synovium. It is therefore likely that a substantial fraction of infiltrating cells in RA may be 'innocent bystander' cells, a possibility which may explain the aforementioned difficulty in detecting $\mathrm{T}$ cell derived cytokines in rheumatoid synovium. That only a fraction of synovial $T$ cells in RA is activated may at least partially explain difficulties in identifying consistent patterns of $\mathrm{T}$ cell receptor $\mathrm{V}$ region gene usage among unselected synovial $\mathrm{T}$ cells.

Emerging evidence indicates that adhesion molecules can also function as costimulatory receptors for $\mathrm{T}$ cells (and other cells such as monocytes and neutrophils). Engagement of several integrins potentiates $\mathrm{T}$ cell proliferation induced by cross linking of the T cell receptor/ CD3 complex on T cells. ${ }^{51-53}$ Binding of the $\alpha 5 \beta 1$ integrin to fibronectin induces expression of AP-1, a transcription factor necessary for IL-2 gene expression. ${ }^{54}$ Another integrin, $\alpha v \beta 3$, functions as a costimulatory molecule for IL-4 production in $\gamma \delta \mathrm{T}$ cells. ${ }^{55}$ Thus interactions between $T$ cell integrins and their respective matrix molecule ligands can exert important influences on the activation and function of these cells.

\section{T cell proteases}

Transendothelial migration of activated $T$ cells involves as yet less defined proteolytic processes. Specialised granules within the cytoplasm of cytolytic $\mathrm{T}$ lymphocytes contain a unique set of proteins that are responsible for the cytolytic activity of these cells (for review, see ref 56). The major constituents are the pore-forming protein perforin (cytolysin) and several highly homologous serine proteases, termed granzymes. With regard to the molecular mechanisms involved in the migration of $T$ cells through vascular endothelial basement membranes, we were able to show that $T$ cell specific serine proteinase 1 (granzyme A) partially degrades basement membrane collagen type IV by cleavage of the $\alpha 2$ (IV) chain within the native molecule, ${ }^{57}$ raising the possibility that this protease may facilitate the movement of $T$ cells through vascular basement membranes into inflammatory foci. Interestingly, both CD4+ and CD8+ lymphocytes from the synovial fluid of patients with RA express perforin and granzyme A. ${ }^{58}$

\section{Humoral responses in RA}

As $R F$ is characteristically present in the serum and synovial fluid of about $80 \%$ of patients 
with RA, efforts have been directed towards delineating the molecular basis of expression of this prototypic autoantibody in RA. Whether polyclonal or antigen driven mechanisms contribute to RF expression in RA remains uncertain; however, RF present in autoimmune $\mathrm{MRL} / \mathrm{lpr}$ mice exhibits patterns of variable region somatic mutations most consistent with an antigen driven response. ${ }^{59}$ Similar conclusions have been reached for antibodies to DNA also present in these mice. ${ }^{60}$ A useful approach for studying the molecular basis of RF expression in man has been the development of structurally defined monoclonal antibody anti-idiotypic reagents. Two such monoclonal antibodies, designated $17 \cdot 109^{61}$ and $6 \mathrm{~B} 6 \cdot 6,{ }^{62}$ recognise distinct VKIII light chain idiotopes expressed by about two thirds of IgMk RF paraproteins. ${ }^{63}$ The $17 \cdot 109$ and $6 \mathrm{~B} 6 \cdot 6$ cross reactive idiotopes (CRIs) are probably encoded by distinct germline $\mathrm{VK}$ genes designated Humkv $325^{64}$ and Humkv $328^{65}$ respectively. $6 \mathrm{~B} 6 \cdot 6 \mathrm{CRI}(+)$ light chains are members of the VkIIIa sub-subgroup, whereas $17 \cdot 109(\mathrm{CRI})(+)$ light chains are members of the VkIIIb sub-subgroup. ${ }^{61-63}$

Efforts have also been directed toward defining CRI shared by heavy chain $\mathrm{V}$ regions of RF paraproteins. For example, monoclonal antibody $\mathrm{G} 6$ recognises a $\mathrm{V}_{\mathrm{H}} 1 \mathrm{CRI}$ encoded by the germline $V_{H}$ gene closely related or identical to hv3005. ${ }^{66-69}$ Another subgroup of RF contains heavy chains recognised by monoclonal antibodies LC1, 5-14, and 6-10; these CRIs are encoded by a $\mathrm{V}_{\mathrm{H}} 4$ gene(s) yet to be precisely identified. ${ }^{70}$ The demonstration that a limited number of germline immunoglobulin $\mathrm{V}$ region genes (for example, Humkv 325 and Humkv 328) encode a substantial fraction of IgM RF paraproteins suggested that these $\mathrm{V}$ genes might also contribute to the expression of RF in RA. Serological analyses of serum $R F$ using monoclonal antibodies identifying germline encoded RF associated CRIs (for example, $17 \cdot 109$ and $6 \mathrm{~B} 6 \cdot 6$ ) have indicated that a substantial proportion of patients with RA synthesise some RF bearing either the 17.109 or 6 B6.6 VKIII CRI. ${ }^{6271} 72$ Only a negligible fraction of $R F$ in individual serum samples, however, appeared to express either CRI. These observations are in striking contrast with the dominance of these idiotopes among RF paraproteins and suggest either that germline Humkv 325 and Humkv 328 (or closely related genes) encode only a small proportion of $R F$ in RA or that extensive mutation of genes encoding RF may occur in the disease. Circumstantial evidence supporting a role for somatic mutation in accounting for the low proportion of $6 \mathrm{~B} 6 \cdot 6$ and $17 \cdot 109 \mathrm{CRI}(+) \mathrm{RF}$ in RA has come from studies of a cDNA library generated from synovial cell mRNA of a patient with RA expressing low levels of $17 \cdot 109$ and $6 \mathrm{~B} 6.6 \mathrm{CRI}(+) \mathrm{RF}$ in her serum and synovial fluid. ${ }^{73}$ Unexpectedly, $27 \%$ of $\kappa$ light chain clones sampled from this patient's synovial library were drawn from the two germline $\mathrm{V}$ region elements, Humkv 325 and Humkv 328. These clones showed con- siderable somatic mutations with a pattern most consistent with antigen driven selection. ${ }^{73}$ Unfortunately, the design of this study did not permit analysis of the specificity of the intact antibodies using these light chain sequences.

An alternative approach which is being used to investigate the $\mathrm{V}$ region diversity of $\mathrm{RF}$ in $R A$ entails analysis of $V$ region sequences of $R F$ elaborated by cloned B cell lines (or hybridomas) obtained from healthy controls and patients with RA. These studies, still in their infancy, indicate that multiple $V_{H}$ and $V_{L}$ genes can encode RF in RA. Both essentially unmodified germline sequences and mutated $\mathrm{V}$ region sequences, consistent with antigen selection, have been found. ${ }^{69}$ 74-76 It therefore seems that the highly restricted pattern of $\mathrm{V}$ gene utilisation, seen among RF paraproteins, is not shared by RF secreting $B$ cell lines rescued from healthy subjects and patients with RA. Caution must be exercised in interpreting these results, however, as the precise relation between cloned B cell lines and autoantibody expression in vivo is far from established.

Although serological studies have the advantage of directly analysing RF expression in vivo, they are constrained by the limited number of monoclonal antibodies recognising structurally defined CRIs that are currently available. Moreover, this approach is unable to distinguish between the influence of somatic mutation of a particular germline gene (with consequent loss of germline encoded CRIs) and the use of alternative germline genes. Application of both serological and cell line analyses to investigation of RF expressed in the same subject offers the most promise of ultimately elucidating the genetic origin of RF in RA. Moreover, such studies should reveal the relative importance of antigen selection versus polyclonal activation in expression of these autoantibodies.

\section{Animal models}

One major difficulty in elucidating the early features and sequence of events in the pathogenesis of RA has been the lack of an appropriate animal model. Following the original discovery in Dr Kang's laboratory that immunisation of rodents with collagen type II induces an inflammatory polyarthritis, ${ }^{77}$ subsequent investigations have shown that the disease can be transferred by $T$ cell clones, that $T$ cell deficient animals do not develop arthritis, and that the disease can be abrogated with antibodies to CD4 (for review see refs 78 and 79). The direct relevance of the type II collagen arthritis model to the pathogenesis of RA remains uncertain, though the presence of $T$ cells reactive with collagen type II in the synovium of patients with RA is of interest in this regard.

Arthritis can also be induced by the parenteral administration of a group A streptococcal cell wall peptidoglycan groupspecific polysaccharide. ${ }^{80}$ This latter model has provided important insights into the role of cytokines and growth factors in the regulation 
of synovial cell growth associated with joint destruction. ${ }^{81}$ Moreover, this model is of further interest because an abnormally functioning hypothalamic-pituitary-adrenal axis, reflected by low endogenous corticosteroid production, contributes to disease susceptibility. ${ }^{82}$ A provocative preliminary report suggests that patients with $\mathrm{RA}$ also have a defective hypothalamic-pituitary-adrenal axis response to immune stimuli which is not attributable to chronic inflammation itself as it was not seen in patients with osteomyelitis. ${ }^{83}$

With Dr John Mountz, our group recently developed a superantigen arthritis model using a $T$ cell receptor $V \beta \quad 8.2$ transgenic mouse in which all $T$ cells are reactive with staphylococcal enterotoxin $\beta$ by virtue of expression of the $\mathrm{V} \beta \quad 8.2 \mathrm{~T}$ cell receptor transgene. ${ }^{84}$ The arthritis develops within 20 days of an intra-articular injection of a single dose of staphylococcal enterotoxin $\beta$; the recipient lpr transgenic mice exhibit a tolerance defect in T cells recognising the staphylococcal enterotoxin $\beta-\mathrm{MHC}$ class II molecule complex, which biases the $T$ cell response away from anergy induction and towards activation. Presumably, sustained activation of T cells in this model triggers a chronic inflammatory response. Interestingly, staphylococcal enterotoxin A induces expression of IL-6 and IL-8 in rheumatoid synovial cells. ${ }^{85}$

Recently, infectious models have been developed with the hope of providing insight into the pathogenesis of chronic inflammatory arthritis. Infectious agents, both bacterial and viral, have long been known to have the potential for triggering inflammatory polyarthritides. In this regard, caprine arthritisencephalitis virus, a lentivirus in the subfamily of retroviruses, infects cells of the macrophage lineage in goats and triggers a progressive arthropathy. ${ }^{86}$ The Lyme arthritis spirochaete, Borrelia burgdorferi, has been shown to induce both a progressive and destructive polyarthritis, ${ }^{87}$ as well as severe systemic lesions in severe combined immunodeficiency mice. ${ }^{88}$ These studies may facilitate re-evaluation of the role of infectious agents in the pathogenesis of chronic inflammatory arthritis.

\section{Synovial hyperplasia}

One major difficulty in elucidating the early events in spontaneous destructive arthritis has been overcome by using the MRL-lpr/lpr mouse strain, because these mice develop a spontaneous RA-like destruction of articular cartilage and bone in addition to expressing RFs and antibodies against collagen type II. ${ }^{89}$ The initial disease in joints of MRL-lpr/lpr mice resembles the synovial cells with a transformed appearance described by Fassbender in human RA. ${ }^{5}$ Most strikingly, the initial proliferation, attachment, and invasion of these cells into cartilage or bone, or both, appears in the absence of inflammatory cells at the sites of destruction, including polymorphonuclear leucocytes, lymphocytes, and mast cells. After initial cartilage and bone destruction, inflammatory cells then appear in the subsynovium and are largely associated with the development of vascular lesions resembling the features of rheumatoid pannus in the human joint. The pathological similarities between the joint lesions in MRLlpr/lpr mice and human RA prompted us to undertake a more detailed characterisation of the synovial cells involved in joint destruction in RA. Immunohistological studies indicated that most of the cells with a transformed appearance $(50-70 \%)$ in RA seem to be derived from the monocyte/macrophage $(M \phi)$ lineage. A much smaller proportion of cells (5-10\%) proliferates in vitro, particularly large stellate shaped cells with a transformed appearance. ${ }^{6}$ These data suggest that only a small proportion of the resident synovial cells in RA proliferates and that most cells in rheumatoid synovial hyperplasia originate from bone marrow. ${ }^{60}$ Based on these observations, a major goal of our laboratory has been to study the role of transcriptional factors in regulating synovial cell proliferation and function.

In view of evidence that several cellular proto-oncogenes have a control role in regulating cell proliferation and that certain oncogenes encoding nuclear proteins, such as myc and myb, cooperate with an activated ras gene in the transformation of cells, ${ }^{91}$ we examined the expression of these protooncogenes in synovial tissue from patients with destructive RA. ${ }^{6}$ Ras and myc oncoproteins could be detected in about $70 \%$ of the patients with RA and were largely restricted to the synovial cells attached to sites of cartilage and bone destruction. ${ }^{92}$ Despite the fact that cooperation between oncogenes has been described in other systems, ${ }^{93}$ it is not established in rheumatoid synovial cells. Interestingly, however, the cysteine proteinase cathepsin L, previously shown to be the major ras induced protein in ras transformed cells, ${ }^{94}$ colocalised with ras and myc expression in about $50 \%$ of the cases of RA studied. ${ }^{92}$ Negligible expression of these oncogenes was detected in inflammatory osteoarthritis. Subsequent studies also showed that cathepsin $B$ occurred at sites of synovial attachment to cartilage and bone in rheumatoid joints. ${ }^{95}$ The secretion of active forms of cathepsins B and $\mathrm{L}$ by ras oncogene-expressing Kirsten virus transformed fibroblasts ${ }^{96}$ and the colocalisation of ras and myc with these cathepsins in RA suggest that these oncoproteins are involved in the upregulation of cysteine proteinases in rheumatoid synovium. Evidence that cathepsins B and L degrade cartilage collagen types II, IX, and $\mathrm{XI}^{97}$ and cartilage proteoglycan aggregates ${ }^{98}$ suggests that these proteinases contribute to joint destruction in RA. Earlier studies have convincingly implicated collagenase in rheumatoid joint destruction. ${ }^{99}$ In this regard, fos and the early growth response gene 1 (egr-1), an inducible gene encoding a zinc finger protein containing two AP-1 binding sites and a sequence homologous to the response element of the c-fos promoter, ${ }^{100}$ have been identified in collagenase-producing rheumatoid synovial lining cells. ${ }^{101}$ Although the role of fos, jun, and 
the AP-1 complex in cell proliferation and transformation is just beginning to emerge, ${ }^{102}$ it is of interest that an AP-1 site and fos are not only involved in the transcriptional control of collagenase but have also been implicated in the basal expression of stromelysin, the other major metalloproteinase that degrades matrix proteins. ${ }^{103}$

In view of the observations that both in human $\mathrm{RA}^{5}{ }^{104}$ and in the spontaneous MRLlpr/lpr arthropathy ${ }^{105}$ cartilage and bone erosions occur exclusively at sites of synovial attachment, it seems likely that a critical cellmatrix interaction(s) occurs. It is well established that various cell types express characteristic patterns of transmembrane adhesion receptors (see above) which recognise and interact with specific types of collagen and collagen associated glycoproteins (for review see ref 106) and, therefore, it is of current interest to delineate the molecular and structural basis of attachment of rheumatoid synovial cells to cartilage and bone matrix components. It should be stressed that fragments of degraded matrix molecules may also regulate expression of connective tissue degrading enzymes. This concept was fostered by the discovery that partially degraded but not native fibronectin induces collagenase and stromelysin expression in synovial fibroblasts following interaction with fibronectin receptors. ${ }^{107}$ These data suggest that the synthesis of proteolytic enzymes in the rheumatoid joint is not only under the control of certain cytokines ${ }^{79} 81$ but is probably also regulated by products generated by the destructive process itself. Both mechanisms may be crucial to the perpetuation of synovial inflammation.

Based on the observation that synovial hyperplasia in RA is associated with a transformed appearing phenotype of the proliferating synovial cells expressing ras and myc oncogenes, ${ }^{108}$ we searched for evidence of transforming factors, especially retroviral antigens, in the rheumatoid synovium. Immunohistology showed reactivity with antibodies against HTLV-I p19 and p24 in the synovium, but as the same patients were seronegative for HTLV-I we concluded that antigens cross reactive with or related to these HTLV-I constituents were present in the synovium. ${ }^{109}$ Studies in our laboratory designed to detect collagen fibrils in synovial fluid, ${ }^{13}$ however, led to the unanticipated detection of virus-like particles within the dense meshwork of proteinaceous aggregates present in rheumatoid synovial fluids. ${ }^{110}$ Subsequent studies, including immunoelectron microscopy, have shown the presence in five of eight cases of RA of spherical particles $200 \mathrm{~nm}$ in diameter and a distinct eccentrically located internal core with an average size of 70 $\mathrm{nm}$, lacking epitopes for HTLV-I p19 and HIV-I p24 (Stransky G, Aicher W K, Moreland L W, et al, unpublished data). These particles bear a striking resemblance to type C retroviral particles but do not resemble any of the known human retroviruses, including particles derived from known endogenous retroviral structures. ${ }^{111} \mathrm{~A}$ retroviral origin for these particles is not only suggested by their morphological appearance but also by the concomitant spontaneous and constitutive expression of the cellular zinc finger transcription factor Z-225 in short and long term cultures of rheumatoid synovial cells. ${ }^{112}$ The constitutive expression of Z-225, resembling egr-1, has only been reported for cells transformed by HTLV-I or HTLV-II. ${ }^{13}$ In addition, recent studies have shown that synoviocytes derived from rheumatoid tissue exhibit reverse transcriptase activity. ${ }^{114}$ Thus we are attracted to the possibility that a hitherto unknown retrovirus may play a part in the pathogenesis of RA. Figure 2 depicts a
Figure 2 Hypothesis for the aetiopathogenesis of the aetiopathogenesis $P D G F=$ platelet derived growth factor; IL-1/-6=interleukin 1/6; $T N F \alpha=$ tumour necrosis factor $\alpha$; $G M-C S F=$ granulocyte-macrophage colony stimulating factor.

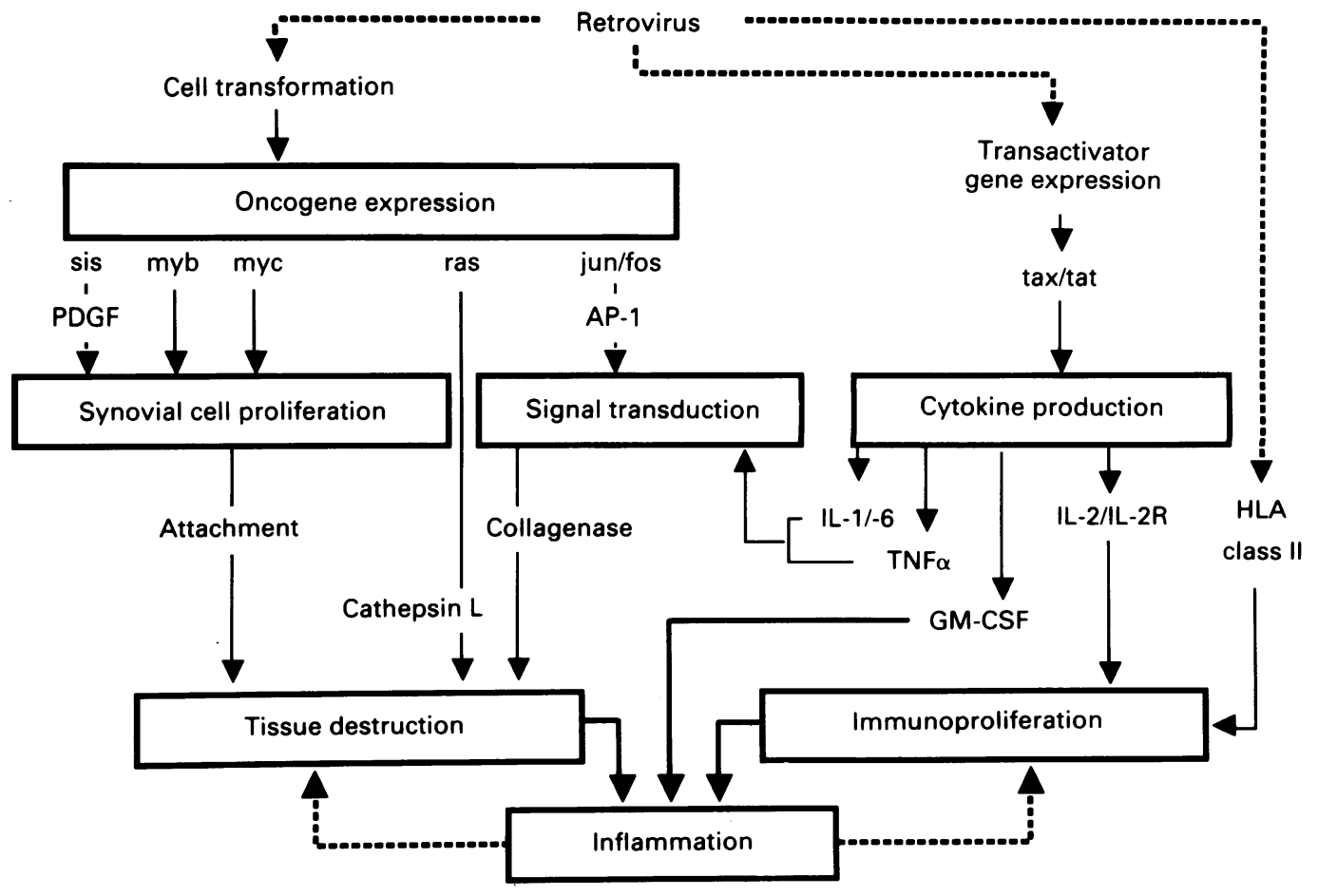


working hypothesis for the aetiopathogenesis of RA. Such a hypothesis could account for the two dominant cellular processes operating in rheumatoid joint destruction (synovial hyperplasia and $\mathrm{T}$ cell dependent immune responses) and would be consistent with a genetic basis for susceptibility to the disease. ${ }^{8}$ Moreover, it could explain the upregulation of proto-oncogenes in the transformed appearing proliferating synovial lining as well as the abnormal humoral and cellular immune responses. In this regard, it is of interest that an inflammatory arthropathy resembling certain features of RA occurs in HTLV-I transgenic mice. ${ }^{115}$ It is also intriguing that HTLV transactivator proteins tat and tax are able to induce the expression of several cellular genes which have been implicated in various aspects of the pathogenesis of RA, including c-fos, ${ }^{116}$ granulocyte-macrophage colony stimulating factor, ${ }^{117}$ the c-sis proto-oncogene encoding for the platelet derived growth factor $\mathrm{B}$ chain ${ }^{118}$ and MHC class II genes. ${ }^{119}$ Last, but not least, this hypothesis would also explain why current antirheumatic treatment is of limited effectiveness in halting progression of joint destruction in RA.

1 Lipsky P E, Davis L S, Cush J J, Oppenheimer-Marks N. The role of cytokines in the pathogenesis of rheumatoid arthritis. Springer Semin Immunopathol 1989; 11: 123-62.

2 Arend W, Koopman W J, eds. Molecular biology and the immunopathogenesis of rheumatoid arthritis. Keystone immunopathogenesis of rheumatoid arthritis. Keystone 1991; suppl 15E: 141-87.

3 Gay S, Koopman W J. Immunopathology of rheumatoid arthritis. Current Rheumatology 1989; 1: 8-14.

4 Kingsley G, Pitzalis C, Panayi G S. Immunogenetic and cellular immune mechanisms in rheumatoid arthritis: relevance to new therapeutic strategies. $\mathrm{Br} \mathcal{F}$ Rheumato 1990; 29: 58-64.

5 Fassbender H G. Histomorphologic basis of articular cartilage destruction in rheumatoid arthritis. Coll Relat Res 1983; 3: 141-55.

6 Gay S, Gay R E. Cellular basis and oncogene expression of rheumatoid joint destruction. Rheumatol Int 1989; 9: 105-13.

7 Buus S, Sette A, Colon S M, Miles C, Grey H M. The relation between major histocompatibility complex (MHC) restriction and the capacity of Ia to bind immunogenic peptides. Science 1987; 235: 1353-8.

8 Kappler J W, Roehen M, Marrack P. T cell tolerance by clonal elimination in the thymus. Cell 1987; 49: 273-80.

9 Herman A, Kappler J W, Marrack P, Pullen A M Superantigens: mechanism of T-cell stimulation and role in immune responses. Annu Rev Immunol 1991; 9: 745-72.

10 Harris E D Jr. Rheumatoid arthritis: pathophysiology and implications for therapy. $N$ Engl $\mathcal{f}$ Med 1990; 322: 1277-89.

11 Firestein G S, Zvaifler N J. How important are T cells in chronic rheumatoid synovitis? Arthritis Rheum 1990; 33: chronic

12 Itescu S, Mathur-Wagh U, Skovron M L, Brancato L J. HLA-B35 is associated with accelerated progression to AIDS. F Acquir Immune Defic Syndr 1992; 5: 37-45.

13 Moreland L W, Stewart T, Gay R E, Huang G-Q McGee N, Gay S. Immunohistologic demonstration of type II collagen in synovial fluid phagocytes of osteoarthritis and rheumatoid arthritis patients. Arthritis Rheum 1989; 32: 1458-64.

14 Gregersen P K, Silver J, Winchester R J. The shared epitope hypothesis: an approach to understanding the molecular genetics of susceptibility to rheumatoid molecular genetics of susceptibility to
arthritis. Arthritis Rheum 1987; 30: 1205-13.

15 Van Boxel J A, Paget S A. Predominantly T-cell infiltrate in rheumatoid synovial membrane. $N$ Engl f Med 1975 ; 293: $517-20$.

16 Burmester G R, Jahn B, Gramatzki M, Zacher J, Kalden $J R$. Activated T cells in vivo and in vitro; divergence in expression of Tac and Ia antigens in the nonblastoid smal $T$ cells of inflammation and normal $T$ cells activated in vitro. F Immunol 1984; 133: 1230-4.

17 Shiroky J B, Yocum D E, Wilder R L, Klippel J H. Experimental basis of innovative therapies of rheumatoid arthritis. Concepts Immunopathol 1989; 7: 106-44.

18 Herzog C, Walker C, Müller W, et al. Anti-CD4 antibody treatment of patients with rheumatoid arthritis: I. Effect on clinical course and circulating $\mathrm{T}$ cells. $\mathcal{f}$ Autoimmun 1989; 2: 627-42.

19 Horneff G, Burmester G R, Emmrich F, Kalden J R Treatment of rheumatoid arthritis with an anti-CD4 monoclonal antibody. Arthritis Rheum 1991; 34: 129-40.

20 Reiter C, Kakavand B, Rieber E P, Schattenkirchner M Riethmüller G, Krüger K. Treatment of rheumatoid arthritis with monoclonal CD4 antibody M-T151. Arthritis Rheum 1991; 34: 525-36.

21 Calabrese L H, Wilke W S, Perkins A D, Tubbs R R Rheumatoid arthritis complicated by infection with human immunodeficiency virus and the development of Sjögren's syndrome. Arthritis Rheum 1989; 32: 1453-7.

22 Bijlsma J W J, Derksen R W H M, Huber-Bruning O Borleffs J C C. Does AIDS 'cure' rheumatoid arthritis? Ann Rheum Dis 1988; 47: 350-1.

23 Paliard X, West S G, Lafferty J A, et al. Evidence for the effects of a superantigen in rheumatoid arthritis. Science 1991; 253: 325-9.

24 Uematsu Y, Wege H, Straus A, et al. The T-cell-receptor repertoire in the synovial fluid of a patient with rheumatoid arthritis is polyclonal. Proc Natl Acad Sci USA 1991; 88: 8534-8.

25 Howell M D, Diveley J P, Lundeen K A, et al. Limited $T$-cell receptor $\beta$-chain heterogeneity among interleukin 2 receptor-positive synovial $T$ cells suggests a role for superantigen in rheumatoid arthritis. Proc Natl Acad Sci $U S A$ 1991; 88: 10921-5.

26 Cooper S M, Dier D L, Roessner K D, Budd R C, Nicklas $J$ A. Diversity of rheumatoid synovial tissue $T$ cells by $T$ cell receptor analysis. Oligoclonal expansion in
interleukin-2-responsive cells. Arthritis Rheum 1991; 34: 537-46.

27 Abe J, Forrester J, Nakahara T, Lafferty J A, Kotzin B L, Leung D Y M. Selective stimulation of human T cells with streptococcal erythrogenic toxins $\mathrm{A}$ and $\mathrm{B}$. F Immunol with streptococcal ery

28 Choi Y, Kotzin B, Herron L, Callahan J, Marrack P, Kappler J. Interaction of Staphylococcus aureus toxin 'superantigens' with human T cells. Proc Natl Acad Sci USA 1989; 86: 8941-5.

29 Jores R, Alzari P M, Meo T. Resolution of hypervariable regions in T-cell receptor beta chains by a modified WuKabat index of amino acid diversity. Proc Natl Acad Sci USA 1990; 87: 9138-42.

30 Choi Y, Herman A, DiGiusto D, Wade T, Marrack P, Kappler J. Residues of the variable region of the T-cellreceptor beta-chain that interact with $\mathrm{S}$. aureus toxin superantigens. Nature 1990; 346: 471-3.

31 Cazenave P A, March PN, Jouvin-Marche E, et al. V beta 17 gene polymorphisms in wild-derived mouse strains: two amino acid substitutions in the $\mathrm{V}$ beta 17 region greatly alter T cell receptor specificity. Cell 1990; 63: 717-28.

32 Baccala R, Smith L R, Vestberg M, Peterson P A, Cole B C, Theofilopoulos A N. Mycoplasma arthritidis mitogen: $V \beta$ engaged in mice, rats, and humans, and requirements of HLA-DR $\alpha$ for presentation. Arthritis Rheum 1992; 35: 434-42.

33 Davies T F, Martin A, Concepcion E S, Graves P, Cohen L, Ben-Nun A. Evidence of limited variability of antigen receptors on intrathyroidal T cells in autoimmune antigen receptors on intrathyroidal T cells in autoimn

34 Dayan C M, Londei M, Corcoran A E, et al. Autoantigen recognition by thyroid-infiltrating $\mathrm{T}$ cells in Graves disease. Proc Natl Acad Sci USA 1991; 88: 7415-9.

35 Londei M, Savill C M, Verhoef A, et al. Persistence of collagen type II-specific T-cell clones in the synovial membrane of a patient with rheumatoid arthritis. Proc Natl Acad Sci USA 1989; 86: 636-40.

36 Yan $T$, Burkhardt $H$, Ritter $H$, et al. Specificity and $T$ cell receptor $\beta$ chain usage of a human collagen type IIreactive $\mathrm{T}$ cell clone derived from a healthy individual. Eur F Immunol 1992; 22: 51-6.

37 Van Eden W, Thole J E R, van der Zee R, et al. Cloning of the mycobacterial epitope recognized by $\mathrm{T}$ lymphocytes of the mycobacterial epitope recognized by T ly

38 Van Eden W, Holoshitz J, Weve Z, Frenkel A, Klajman A, Cohen I R. Arthritis induced by a T-lymphocyte clone that responds to mycobacterium tuberculosis and to cartilage proteoglycans. Proc Natl Acad Sci USA 1985; 82: 5117-20.

39 Karlsson-Parra A, Söderström K, Ferm M, Ivanyi J, Kiessling R, Klareskog L. Presence of human $65 \mathrm{kD}$ heat shock protein (hsp) in inflamed joints and subcutaneous nodules of RA patients. Scand f Immunol 1990; 31: 283-8.

40 Li S G, Quayle A J, Shen Y, et al. Mycobacteria and human heat shock protein-specific cytotoxic lymphocytes in
rheumatoid synovial inflammation. Arthritis Rheum 1992; 35: $270-81$.

41 Fischer H P, Sharrock C E M, Colston M J, Panayi G S. Limiting dilution analysis of proliferative $T$ cell responses to mycobacterial $65-\mathrm{kDa}$ heat-shock protein fails to show significant frequency differences between synovial fluid and peripheral blood of patients with rheumatoid arthritis. Eur f Immunol 1991; 21: 2937-41.

42 Butcher E C. Leukocyte-endothelial cell recognition: three (or more) steps to specificity and diversity. Cell 1991;67: 1033-6.

43 von Andrian $\mathrm{U} \mathrm{H}$, Chambers J D, McEvoy L M, Bargatze $R$ F, Arfors K-E, Butcher E C. Two-step model of leukocyte-endothelial cell interaction in inflammation: distinct roles for LECAM-1 and leukocyte $\beta 2$ integrins in vivo. Proc Natl Acad Sci USA 1991; 88: 7538-42. 
44 Smith C W, Kishimoto T K, Abbass O, et al. Chemotactic factors regulate lectin adhesion molecule 1 (LECAM-1)dependent neutrophil adhesion to cytokine-stimulated
endothelial cells in vitro. $₹$ Clin Invest $1991 ; 87: 609-18$.

45 Abbot S E, Kaul A, Stevens C R, Blake D R. Isolation and culture of synovial microvascular endothelial cells. Characterization and assessment of adhesion molecule expression. Arthritis Rheum 1992; 35: 401-5.

46 Kavanaugh A F, Lightfoot E, Lipsky P E, OppenheimerMarks N. Role of CD11/CD18 in adhesion and Marks $N$. Role of $\mathrm{CD} 11 / \mathrm{CD} 18$ in adhesion and
transendothelial migration of $\mathrm{T}$ cells. Analysis utilizing transendothelial migration of $\mathrm{T}$ cells. Analysis utilizing 4149-56.

47 Oppenheimer-Marks N, Davis L S, Bogue D T, Ramberg J, Lipsky P E. Differential utilization of ICAM-1 and VCAM-1 during the adhesion and transendothelial migration of human T lymphocytes. F Immunol 1991; 147: 2913-21.

48 Sanders M E, Makgoba M W, Sharrow S O, et al. Human memory $T$ lymphocytes express increased levels of three cell adhesion molecules (LFA-3, CD2, and LFA-1) and cell adhesion molecules (LFA-3, CD2, and LFA-1) and three other molecules (UCHL1, CDw29, Pgp-1) and
have enhanced IFN- $\gamma$ production. $\mathcal{F}$ Immunol 1988; 140: 1401-7.

49 Shimizu Y, Van Seventer G A, Horgan K J, Shaw S Regulated expression and binding of three VLA ( $\beta 1)$ integrin receptors on T cells. Nature 1990; 345: 250-3.

50 Pitzalis C, Kingsley G, Haskard D, Panayi G. The preferential accumulation of helper-inducer $T$ lymphocytes in inflammatory lesions: evidence for regulation by selective endothelial and homotypic adhesion. Eur ₹ Immunol 1988; 18: 1397-404.

51 Matsuyama Y, Yamada A, Kay J, et al. Activation of CD4 cells by fibronectin and anti-CD 3 antibody. 7 Exp Med cells by fibronectin 170 : $1133-48$.

52 Shimizu Y, van Seventer G A, Horgan K J, Shaw S Costimulation of proliferative responses of resting CD4 $T$ cells by the interaction of VLA-4 and VLA-5 with fibronectin or VLA-6 with laminin. F Immunol 1990; 145 59-67.

53 Burkly L C, Jakubowski A, Newman B M, Rosa M D, ChiRosso G, Lobb R. Signaling by vascular adhesion molecule-1 (VCAM-1) through VLA-4 promotes CD-3 dependent $T$ cell proliferation. Eur 7 Immunol 1991; 21: 2871-5.

54 Yamada A, Nikaida T, Nojima Y, Schlossman S F, Morimoto C. Activation of CD4 $\mathrm{T}$ lymphocytes. Interaction of fibronectin with VLA-5 receptor on CD4 Interaction of fibronectin with VLA-5 receptor on CD4 cells induces the

55 Roberts K, Yokoyama W M, Kehn P J, Shevach E M. The vitronectin receptor serves as an accessory molecule for the activation of a subset of gamma/delta $\mathrm{T}$ cells. $\boldsymbol{f}$ Exp Med 1991; 173: 231-40.

56 Griffiths G M, Mueller C. Expression of perforin and granzymes in vivo: potential diagnostic markers for activated cytotoxic cells. Immunol Today 1991; 12: $415-9$.

57 Simon M M, Kramer M D, Prester M, Gay S. Mouse $T$-cell associated serine proteinase 1 degrades collagen type IV: a structural basis for the migration of type IV: a structural basis for the migration of lymphocytes through vascular

58 Griffiths G M, Alpert S, Lambert E, McGuire J, Weissman I L. Perforin and granzyme A expression identifyin cytolytic lymphocytes in rheumatoid arthritis. Proc Nat Acad Sci USA 1992; 89: 549-53.

59 Schlomchik M J, Marshak-Rothstein A, Wolfowicz C B, Rothstein T L, Weigert M G. The role of clonal selection and somatic mutation in autoimmunity. Nature 1987; 328: 805-11.

60 Schlomchik M J, Mascelli M, Shan $\mathrm{H}$, et al. Structure and function of anti-DNA autoantibodies derived from function of anti-DNA autoantibodies derived from a 84: $9150-4$.

61 Carson D A, Fong S. A common idiotope on human rheumatoid factors identified by a hybridoma antibody. Mol Immunol 1983; 20: 1081-7.

62 Schrohenloher R E, Accavitti M A, Bhown A S, Koopman W J. Monoclonal antibody 6 B6.6 defines a cross-reactive kappa light chain idiotope on human monoclonal and polyclonal rheumatoid factors. Arthritis Rheum 1990; 33: polyclon.

63 Crowley J J, Goldfien R D, Schrohenloher R E, et al. Incidence of three cross-reactive idiotypes on human rheumatoid factor proteins. F Immunol 1988; 140: 3411-8.

64 Radoux V, Chen P P, Sorge J A, Carson D A. A conserved human germline VK gene directly encodes rheumatoid human germline $V_{K}$ gene directly encodes rheuma
factor light chains. $\mathcal{F}$ Exp Med $1986 ; 164: 2119-24$

65 Chen P P, Robbins D L, Jirik F R, Kipps T J, Carson D A. Isolation and characterization of a light chain variable region for human rheumatoid factors. 7 Exp Med 1987 166: $1900-5$.

66 Mageed R A, Dearlove M, Goodall D M, Jefferis R Immunogenic and antigenic epitopes of immunoglobulins. XVII. Monoclonal anti-idiotypes to the heavy chain of human rheumatoid factors. Rheumatol Int 1986; 6: 179-83.

67 Chen P P, Liu M-F, Glass C A, Sinha S, Kipps T J, Carson $D$ A. Characterization of two Ig $V_{H}$ genes which are homologous to human rheumatoid factors. Arthritis Rheum 1989; 32: 72-6.

68 Crowley J J, Mageed R A, Silverman G J, et al. The incidence of a new human cross-reactive idiotype linked to subgroup $\mathrm{V}_{\mathrm{H}}$ III heavy chains. Mol Immunol 1990; 27: 87-94.

69 Pascual V, Randen I, Thompson K, et al. The complete nucleotide sequences of the heavy chain variable regions of six monospecific theumatoid factors derived from Epstein-Barr virus-transformed B cells isolated from the synovial tissue of patients with rheumatoid arthritis. $f$ Clin Invest 1990; 86: 1320-8.

70 Silver G J, Schrohenloher R E, Accavitti M A, Koopman W J, Carson D A. Structural characterization of the second major cross-reactive idiotype group of human rheumatoid factors: association with the $\mathrm{V}_{\mathrm{H}} 4$ gene family. Arthritis Rheum 1990; 33: 1347-60

71 Koopman W J, Schrohenloher R E, Carson D A. Dissociation of expression of two rheumatoid factor crossreactive $\kappa \mathrm{L}$ chain idiotypes in rheumatoid arthritis. $\mathcal{f}$ Immunol 1990; 144: 3468-72.

72 Kouri T, Crowley J, Aho $\mathrm{K}$, et al. Occurrence of two germline-related rheumatoid factor idiotypes in reumatoid arthritis and in non-rheumatoid seropositive individuals. Clin Exp Immunol 1990; 82: 250-6.

73 Lee S K, Bridges S L Jr, Koopman W J, Schroeder H W Jr. The immunoglobulin kappa light chain repertoire expressed in the synovium of a patient with rheumatoid arthritis. Arthritis Rheum 1992; 35: 905-13.

74 Ezaki I, Kanda H, Sakai K, et al. Restricted diversity of the variable region nucleotide sequences of the heavy and light chains of a human rheumatoid factor. Arthritis Rheum 1991; 34: 343-50.

75 Victor K D, Randen I, Thompson K, et al. Rheumatoid factors isolated from patients with autoimmune disorders are derived from germline genes distinct from those encoding the $\mathrm{Wa}, \mathrm{Po}$, and Bla cross-reactive idiotypes. $f$ Clin Invest 1991; 87: 1603-13.

76 Olee T, Lu E W, Huang D-F, et al. Genetic analysis of selfassociating immunoglobulin $G$ rheumatoid factors from two rheumatoid synovia implicates an antigen-driven response. F Exp Med 1992; 175: 831-42.

77 Trentham D E, Townes A S, Kang A H. Autoimmunity to type II collagen: an experimental model of arthritis. $\mathcal{F}$ Exp Med 1977; 146: 857-69.

78 Stuart J M, Watson W C, Kang A H. Collagen autoimmunity and arthritis. FASEB f $1988 ; 2: 2950-6$.

79 Firestein G S. Cytokines in autoimmune diseases. Concepts Immunopathol 1992; 8: 129-60.

80 Wilder R L. Streptococcal wall-induced polyarthritis in rats. In: Greenwald $\mathrm{R} A$, Diamond $\mathrm{H} S$, eds. $C R C$ rats. In: Greenwald $\mathrm{R} A$, Diamond $\mathrm{H}$, eds. CRC Boca Raton, FL: CRC Press, 1988: 33-40.

81 Remmers E F, Lafyatis R, Kumkumian G K, et al. Cytokines and growth regulation of synoviocytes from patients with rheumatoid arthritis and rats with streptococcal cell wall arthritis. Growth Factors 1990; 2 179-88.

82 Sternberg E M, Young W S III, Bernardini R, et al. A central nervous system defect in biosynthesis of corticotropin-releasing hormone is associated with susceptibility to streptococcal cell-wall-induced arthritis in Lewis rats. Proc Natl Acad Sci USA 1989; 86: 4771-5.

83 Panayi G S, Chikanza I C, Petrou P, Kingsley G, Chrouso G. Defective hypothalamic-pituitary adrenal axis function in rheumatoid arthritis is not a consequence of chronic in rheumatoid arthritis is not a consequence
inflammation per se. FASEB $¥ 1991 ; 6:$ A 1448 .

84 Mountz J D, Zhou T, Gay R, et al. Genetic and environment requirements for development of inflammatory arthritis. Arthritis Rheum 1991; 34(suppl): 26.

85 Mourad W, Mehindate K, Schall T J, McColl S R Engagement of major histocompatibility complex class II molecules by superantigen induces inflammatory cytokine gene expression in human rheumatoid fibroblast-like synoviocytes. f Exp Med 1992; 175: 613-6.

86 Banks K L, Jutila M A, Jacobs C A, Michaels F H. Augmentation of lymphocyte and macrophage Augmentation of lymphocyte and macrophage proliferation by caprine arthritis-encephalitis virus Contributes to the development
Rheumatol Int 1989; 9: 123-8.

87 Schaible U E, Kramer M D, Museteanu C, Zimmer G Mossmann $H$, Simon $M$ M. The severe combined immunodeficiency (SCID) mouse: a laboratory model fo the analysis of Lyme arthritis and carditis. $f$ Exp Med 1989; 170: $1427-32$

88 Schaible U E, Gay S, Museteanu C, et al. Lyme borreliosis in the severe combined immunodeficiency (scid) mice manifests predominantly in

89 Koopman W J, Gay S. The MRL-lpr/pr mouse: A model for the study of rheumatoid arthritis. Scand $\mathcal{F}$ Rheumatol Suppl 1988; 75: 284-9.

90 Henderson B, Revell P A, Edwards J C W. Synovial lining hyperplasia in rheumatoid arthritis: dogma and fact. Ann

91 Land H, Parada L F, Weinberg R A. Tumorigenic conversion of primary fibroblasts requires at least two conversion of primary fibroblasts requires at least

92 Trabandt A, Aicher W K, Gay R E, et al. Expression of the collagenolytic and ras-induced cysteine proteinase cathepsin $\mathrm{L}$ and proliferation-associated oncogenes in synovial cells of MRL 4 mice and patients with rheumatoid arthritis. Matrix 1990; 10: 349-61.

93 Hunter T. Cooperation between oncogenes. Cell 1991; 64 249-70.

94 Joseph L J, Chang L C, Stamenkovich D, Sukhatme V P. Complete nucleotide and deduced amino acid sequences of human and murine preprocathepsin L. An abundan 
transcript induced by transformation of fibroblasts. $f$ Clin Invest 1988; 81: $1621-9$

95 Trabandt A, Gay R E, Fassbender H G, Gay S. Cathepsin B in synovial cells at the site of joint destruction in rheumatoid arthritis. Arthritis Rheum 1991; 34: 1441-51.

96 Mason R W, Wilcox D, Wikstrom P, Shaw E N. The identification of active forms of cysteine proteinases in Kirsten-virus-transformed mouse fibroblasts by use of specific radiolabelled inhibitor. Biochem $\mathcal{f}$ 1989; 257: 125-9.

97 Maciewicz RA, Wotton S F, Etherington D J, Duance V C Susceptibility of the cartilage collagens type II, IX and XI to degradation by the cysteine proteinases, cathepsin B and L. FEBS Lett 1990; 269: 189-93.

98 Nguyen Q, Mort J S, Roughley P J. Cartilage proteoglycan aggregate is degraded more extensively by cathepsin I than by cathepsin B. Biochem 7 1990; 266: 569-73.

99 Krane S M, Conca W, Stephenson M L, Amento E P, Goldring M B. Mechanisms of matrix degradation in rheumatoid arthritis. Ann NY Acad Sci 1990; 580 340-54.

100 Sukhatme V P. The Egr transcription factor family: from signal transduction to kidney differentation. Kidney Int 1992; 41: 550-3.

101 Trabandt A, Aicher W K, Gay R E, Sukhatme V P, Fassbender H G, Gay S. Spontaneous expression of immediately early response genes c-fos and egr-1 in collagenase-producing rheumatoid synovial fibroblasts. Rheumatol Int 1992; 12: 53-9.

102 Angel P, Karin M. The role of Jun, Fos and the AP-1 complex in cell-proliferation and transformation. Biochim Biophys Acta 1991; 1072: 129-57.

03 Buttice G, Quinones S, Kurkinen M. The AP-1 site is required for basal expression but is not necessary for TPA response of the stromelysin gene. Nujcleic Acids Res 1991 19: 3723-31.

104 Allard S A, Muirden K D, Maini R N. Correlation of histopathological features of pannus with patterns of damage in different joints in rheumatoid arthritis. Ann Rheum Dis 1991; 50: 278-83.

105 Tanaka A, O'Sullivan F X, Koopman W J, Gay S. Etiopathogenesis of the rheumatoid arthritis-like disease
in MRI $\Omega$ mice: II. Ultrastructural basis of joint in MRL mice: II. Ultrastructural

106 Gay S, Gay R E. Connective tissue structure and function. In: Wyngaarden J B, Smith L H Jr, Bennett J C, eds. Cecil textbook of medicine. 19th ed. Philadelphia: Saunders, 1992: 1491-6.
107 Werb Z, Tremble P M, Behrendtsen O, Crowley E Damsky C H. Signal transduction through the fibronectin receptor induces collagenase and stromelysin gene expression. F Cell Biol 1989; 109: 877-89.

108 Gay S, Tanaka A, Tarkowski A, Gay RE, Fassbender H G Expression of oncogenes ras and myc in proliferating synovial lining cells in rheumatoid arthritis. Arthritis Rheum 1988; 31: R40.

109 Ziegler B, Huang G-Q, Gay R E, Fassbender H G, Gay S Immunohistological localization of HTLV-1 p19- and p24-related antigens in synovial joints of patients with rheumatoid arthritis. Am $\mathcal{F}$ Pathol 1989; 135: 1-5.

110 Stransky G, Moreland L W, Gay R E, Gay S. Virus-like particles (VLP) in synovial fluids from patients with
rheumatoid arthritis (RA). Arthritis Rheum 1990; 33: S143.

111 Larsson E, Kato N, Cohen $M$. Human endogenous proviruses. Curr Top Microbiol Immunol 1989; 148: 115-32.

112 Aicher W K, Gay R E, Stransky G, et al. Detection of Z-225 message in a cDNA library and synovial lining cells of patients with rheumatoid arthritis. Arthritis Rheum 1991; 34: D68.

113 Wright J J, Gunter K C, Mitsuya H, Irving S G, Kelly $\mathrm{K}$, Siebenlist $\mathrm{U}$. Expression of a zinc finger gene in HTLV-I- and HTLV-II-transformed cells. Science 1990; 248: 588-91.

114 Aicher W K, Stransky G, Gay R E, Gay S. Synovial lining cells derived from patients with rheumatoid arthritis (RA) produce reverse transcriptase. Arthritis Rheum 1991; 34(suppl): 177.

115 Iwakura $\mathrm{Y}$, Tosu M, Yoshida E, et al. Induction of inflammatory arthropathy resembling rheumatoid arthritis in mice transgenic for HTLV-I. Science 1991; 253: $1026-8$.

116 Fujii M, Sassone-Corsi P, Verma I M. c-fos promoter trans-activation by the tax ${ }_{1}$ protein of human T-cell leukemia virus type I. Proc Natl Acad Sci USA 1988; 85: 3526-30.

117 Nimer S D, Gasson J C, Hu K, et al. Activation of the GM-CSF promoter by HTLV-I and -II tax proteins. GM-CSF promoter by

118 Ratner L. Regulation of expression of the c-sis protooncogene. Nucleic Acids Res 1989; 17: 4101-5.

119 Hirayama M, Miyadai T, Yokochi $\mathrm{T}$, et al. Infection of human T-lymphotropic virus type I to astrocytes in vitro with induction of the class II major histocompatibility complex. Neurosci Lett 1988; 92: 34-9. 